\title{
Main findings on CT scan and its technological advances: A review
}

\author{
Facina RK ${ }^{1}$, Ferreira NB${ }^{1}$, Ferreira $C^{1}$, Tempest $\mathrm{LM}^{1,2}$, Filho $\mathrm{IJZ}^{2 *}$ and Gubolin $\mathrm{SA}^{1,2}$ \\ ${ }^{1}$ University Center North Paulista (Unorp) - São José do Rio Preto - SP, Brazil \\ ${ }^{2}$ Post graduate and continuing education (Unipos), Street Ipiranga, 3460, São José do Rio Preto SP, Brazil 15020-040
}

\begin{abstract}
Background: Conventional tomography has undergone processes of transformation and innovation, such processes that have led to the spiral CT scan.

Objective: to make a literary review about computed tomography and its technological advances.

Methods: Experimental and clinical studies were included (case reports, retrospective, prospective and randomized trials) with qualitative and / or quantitative analysis. The words were included. A total of 40 articles were found involving. The total of 27 articles were evaluated in full, and 21 were included and discussed in this study.
\end{abstract}

Conclusion: CBCT enhances the professional's confidence in the decision to perform the surgical procedure. The concordance was greater when using CBCT, leading to greater consistency in the type of treatment indicated.

\section{Introduction}

The use of radiation began to have diagnostic purposes in 1895 , by Roentgen's X-ray in Germany. Conventional tomography has undergone processes of transformation and innovation, such processes that have led to the spiral computed tomography (CT) [1-3].

CT scans can be generally classified into two types, this classification refers to the format of the $\mathrm{x}$-ray beam emitted by the apparatus [3-5]. They are the fan-beam and conical beam rays, the first known as Fan Beam and following as Cone Beam Computed Tomography (CBCT). Both have in common, the use of radiation to perform the procedure. However, all the remaining characteristics present differences, such as the size of the device, scanning time, financial cost, image quality and radiation dose [6,7].

Computed tomography (CT) reproduces a layered body session, projecting into three planes of space through the projection of rivers $x$, traversing the structures in depth $[8,9]$, allowing to observe all the structures in slices, including the Mineralized tissue and its threedimensional delimitations. Contrary to Radiography, which projects only one plane of the crossed structure [10].

CT is increasingly being requested in the dental area and is no longer just a medical use, especially in the area of implantology, surgery, orthodontics, and oral diagnosis. CT can achieve sharper, more detailed images in relation to the images obtained by conventional radiography [11]. They have become important in dentistry for evaluation and studies of maxilla and mandible, as well as for implant placement, TMJ investigation, traumatisms, detection of pathologies, dental impaction, degree of root resorption, dental inclinations, analyze dental movements with Invagination in the maxillary sinus, in short, several purposes [12].

The present study aimed to make a literature review about computerized tomography and its technological advances.

\section{Methodology}

Experimental and clinical studies were included (case reports, retrospective, prospective and randomized trials) with qualitative and / or quantitative analysis. Initially, the key words were determined by searching the DeCS tool (Descriptors in Pubmed, Health Sciences, BIREME base) and later verified and validated by MeSh system (Medical Subject Headings, the US National Library of Medicine) in order to achieve consistent search.

\section{Mesh terms}

The words were included Computed tomography; Cone Beam Computed Tomography; Dental Examinations. The literature search was conducted through online databases: Pubmed, Periodicos.com and Google Scholar. It was stipulated deadline, and the related search covering all available literature on virtual libraries.

\section{Series of articles and eligibility}

A total of 40 articles were found involving Computed tomography; Cone Beam Computed Tomography; Dental Examinations. Initially, it was held the exclusion existing title and duplications in accordance with the interest described this work. After this process, the summaries were evaluated and a new exclusion was held. A total of 27 articles were evaluated in full, and 20 were included and discussed in this study.

Correspondence to: Idiberto José Zotarelli Filho, Unipos - Post graduate and continuing education, Street Ipiranga, 3460, São José do Rio Preto SP, Brazil 15020040; Tel: +55(17) 98166-6537 / +55(17) 98803-7459; E-mail: m.zotarelli@gmail.com

Key words: cone beam computed tomography, CBCT, supernumerary teeth

Received: August 04, 2017; Accepted: August 31, 2017; Published: September 04, 2017 


\section{Literature review and discussion}

Cone - Beam Computed Tomography (CBCT) consists of a tube - detector system that performs a single 360 - degree rotation around the patient 's head, producing high image quality results and good geometric accuracy [13]. The image is constructed through the data set obtained by the sequence of projections performed during rotation of the tube-detector system around the irradiated body, and sequentially are processed by means of computer programs, finalizing the shape of the volumetric image [14].

In the computer after reconstruction of the total volume, multiplanar images are generated in axial, coronal and sagittal anatomical planes, as well as in third dimension $[15,16]$. In this procedure, 360 images are drawn, each image being generated by a degree of rotation, and aggregated by the program that accompanies the device, finally producing the three-dimensional model of the head [6].

In the comparison between conventional tomography and concomitant computed tomography, we can first observe that both have good image clarity, but the conventional one presents excellent contrast and the conical beam has low contrast in hard and soft tissue [17]. The limitation of CBCT is the difficult visualization of soft tissue while CT differentiates several types of tissue. The size of the device is also related to the area to be scanned, CT is a large device and allows examination of the whole body [18].

In order to obtain an image in axial sections through 3D multiplanar reconstruction, it is necessary to take several turns around the patient with the $\mathrm{x}$-ray beams [19]. As its image is given by axial cuts, the scanning time is 1 second multiplied by the amount of axial cuts required with exposure to the interrupted radiation. The radiation dose and the financial cost of the exam are considered high. While the CBCT is more compact and allows only the examination of the head and neck region [20].

To obtain an image based on teleradiography, only one turn of the $\mathrm{x}$-ray beam around the body [21] is required. The scanning time is shorter, from 10 to 70 seconds of examination, with 3 to 6 seconds of radiation exposure. The major advantages of $\mathrm{CBCT}$ are the reduction of the financial cost of the examination, and a low dose of radiation, which is approximately 15 times lower than CT [20,21]. However, it is important to emphasize that the radiation dose of CBCT is greater than that of conventional radiographs [21].

The images processed by the CBCT are better visualized due to the lower production of artifacts than in CT. It is presenting much artifact in the presence of metallic materials [15].

Also, the quality and accuracy of the images obtained by the CT and CBCT were evaluated [16,17]. 417 images of teeth and their adjacent structures were analyzed, observing the periodontal space, the enamel dentine interface, the roots and the artifact production. And at its conclusion was recorded the approval of the images in the efficiency of both to assist in the diagnosis and planning [17].

The CBCT stands out in questions of not generating artifacts in the image and of needing a smaller dose of radiation [18]. However, it was not able to generate such satisfactory images for periodontal space analysis. Contrary to the image of CT that in this question was satisfactory. This feature is relevant for the visualization of a root resorption and ankylosis $[18,19]$.

The CBCT is superior to CT in the visualization of the images and its great capacity to evaluate enamel, dentin, cementum, spongy bone and even the periodontal ligament. When referring to CBCT, the i-CAT scanner, one of the most commonly used scanners, is now available [19]. In the market, it presents with properties of $120 \mathrm{Kv}, 37.07 \mathrm{~mA}$, with image resolution of $0.2 \mathrm{~mm}$ of voxel and image acquisition time is $26.9 \mathrm{~s}$ [18].

With the improvement of the tomographs, an advanced scanner was created, with an acquisition time varying from 19 to 37 seconds, with only $90 \mathrm{KVp}$ and $4 \mathrm{~mA}$ [17]. Known as Prexion- 3D that uses small FOVs, it captures up to 1024 images using continuous $x$-ray beams. While the i-CAT has medium and large FOVs, it uses pulsating beam beams to achieve around 306 to 599 images [21].

The Cone Beam-PreXion scanner delivers high-quality images with the fastest processing times. Prexion 3D systems provide the dental community with tools to assist in the confirmation of a diagnosis, and to develop a more complete and accurate treatment plan [21]. Since the use of $\mathrm{CBCT}$ avoids recurring complications of poor planning, which are generated by the misunderstanding of an overlapping or distorted image. These events are frequent in panoramic and periapical radiographs. Its purpose has increased in implant placement plans in the mandible, with easy visualization of the inferior alveolar nerve through a transverse section [20,21].

Endodontists are using high-precision three-dimensional geometric images for treatments of partially calcified atresic root canals, supernumerary canals, and teeth with dilacerated roots $[1,2,20]$. In orthodontics are making great use for locating impacted and impacted teeth. And their relationship with adjacent teeth and structures, assessing the degree of root resorption of adjacent teeth, being a common case with canines that are retained [20].

As well as for an accurate position of the roots and in the investigation of the seasoning-mandibular joint [19]. Surgeons may reduce the risk of surgical complications by observing high-quality images that accurately reproduce noble anatomical structures that may be injured, such as vessels, nerves, and salivary glands [12,19]. As well as assisting in the removal of maxillofacial pathologies, cysts and tumors and in the reconstruction of facial fractures. It should not be disregarded that Prexion's radiation is high compared to conventional radiographs. Therefore, its election must be conscious, but its usefulness should not be indiscriminate, since the Prexion has numerous advantages [21].

\section{Conclusion}

The CBCT increases the professional confidence in the decision to perform the surgical procedure. The concordance was greater when using $\mathrm{CBCT}$, leading to greater consistency in the type of treatment indicated.

\section{Competing interests}

The authors none declare.

\section{References}

1. Ahmad M, Jenny J, Downie M (2012) Application of cone beam computed tomography in oral and maxillofacial surgery. Aust Dent J 57 Suppl 1: 82-94. [Crossref]

2. American Dental Association Council on Scientific Affairs (2012) The use of conebeam computed tomography in dentistry: an advisory statement from the American Dental Association Council on Scientific Affairs. J Am Dent Assoc 143(8): 899-902. [Crossref]

3. Benson BW, Flint DJ, Liang H, Opatowsky MJ (2014) Advances in diagnostic imaging for pathologic conditions of the jaws. Head Neck Pathol 8: 383-391. [Crossref] 
4. Brown J, Jacobs R, Levring Jäghagen E, Lindh C, Baksi G, et al. (2014) Basic training requirements for the use of dental CBCT by dentists: a position paper prepared by the European Academy of DentoMaxilloFacial Radiology. Dentomaxillofac Radiol 43(1). [Crossref]

5. Carter JB, Stone JD, Clark RS, Mercer JE (2016) Applications of Cone-Beam Computed Tomography in Oral and Maxillofacial Surgery: An Overview of Published Indication and Clinical Usage in United States Academic Centers and Oral and Maxillofacial Surgery Practices. J Oral Maxillofac Surg 74: 668-679. [Crossref]

6. Cavalcante JR, Diniz DN, de Melo Queiroz RP, Carreira PFS, luna AGB (2012) Aplicação da tomografia na CTBMF: Relatos de caso. Rev cir traumatol buco-maxilofac 12(2): 53-58.

7. Costa FF (2013) Avaliação da interferência de artefatos metálicos dentários na visualização da integridade radicular utilizando a Tomografia Computadorizada por Feixe Cônico. 2013. Tese (Doutorado em Clínica Integrada) - Faculdade de Odontologia, Universidade de São Paulo, São Paulo.

8. Dula K, Benic GI, Bornstein M, Dagassan-Berndt D, Filippi A, et al. (2015) Sadmfr guidelines for the use of Cone-Beam Computed Tomography/ Digital Volume Tomography. Swiss Dent J 125(9): 945-953. [Crossref]

9. Dula K, Bornstein MM, Buser D, Dagassan-Berndt D, Ettlin DA, et al. (2014) SADMFR guidelines for the use of Cone-Beam Computed Tomography/ Digital Volume Tomography. Swiss Dent J 124: 1169-1183. [Crossref]

10. Federal Guidance Report 14: Radiation Protection Guidance for Diagnostic and Interventional X-ray Procedures; 2012. Washington, DC, Interagency Working Groupon Medical Radiation, US. Environmental Protection Agency (EPA) 2012.

11. Gohel A, Villa A, Sakai O (2016) Benign Jaw Lesions. Dent Clin North Am 60: 125141. [Crossref]
12. Horner K, O’Malley L, Taylor K, Glenny AM (2015) Guidelines for clinical use of CBCT: a review. Dentomaxillofac Radiol 44(1). [Crossref]

13. Jaju PP, Jaju SP (2015) Cone-beam computed tomography: Time to move from ALARA to ALADA. Imaging Sci Dent 45: 263-265. [Crossref]

14. Carter JB, Stone JD, Clark RS, Mercer JE (2016) Applications of Cone-Beam Computed Tomography in Oral and Maxillofacial Surgery: An Overview of Published Indications and Clinical Usage in United States Academic Centers and Oral and Maxillofacial Surgery Practices. J Oral Maxillofac Surg 74: 668-679. [Crossref]

15. Kämmerer PW, Thiem D, Eisenbeiß C, Dau M, Schulze RK, et al. (2016) Surgical evaluation of panoramic radiography and cone beam computed tomography for therapy planning of bisphosphonate-related osteonecrosis of the jaws. Oral Surg Oral Med Oral Pathol Oral Radiol 121(4): 419-424. [Crossref]

16. Kaneda T, Minami M, Kurabayashi T (2003) Benign odontogenic tumors of the mandible and maxilla. Neuroimaging Clin N Am 13: 495-507. [Crossref]

17. Kiljunen T, Kaasalainen T, Suomalainen A, Kortesniemi M (2015) Dental cone beam CT: A review. Phys Med 31(8): 884-860. [Crossref]

18. Koçak-Berberoğlu H, Çakarer S, Brkić A, Koseoglu BG, Altuğ-Aydil B, et al. (2012) Three-dimensional cone-beam computed tomography for diagnosis of keratocystic odontogenic tumours; evaluation of four cases. Med Oral Patol Oral Cir Bucal 17(6): e1000-e1005. [Crossref]

19. Koong B (2012) The basic principles of radiological interpretation. Aust Dent J 57 Suppl 1: 33-39. [Crossref]

20. Lopes IA, Tucunduva RM, Handem RH, Capelozza AL (2017) Study of the frequency and location of incidental findings of the maxillofacial region in diferente fields of view in CBCT scans. Dentomaxillofac Radiol 46(1). [Crossref]

21. Mceowen D (2008) Prexion 3-D: dentistry in the third dimension. Dental Tribune.

Copyright: (2017 Facina RK. This is an open-access article distributed under the terms of the Creative Commons Attribution License, which permits unrestricted use, distribution, and reproduction in any medium, provided the original author and source are credited. 